\title{
Nonspecific Interstitial Pneumonitis in HIV-infected Patients
}

\author{
Bobbak Vahid \\ Thomas Jefferson University
}

Follow this and additional works at: https://jdc.jefferson.edu/tmf

Part of the Medical Immunology Commons

Let us know how access to this document benefits you

\section{Recommended Citation}

Vahid, Bobbak (2003) "Nonspecific Interstitial Pneumonitis in HIV-infected Patients," The Medicine Forum: Vol. 4 , Article 5.

DOI: https://doi.org/10.29046/TMF.004.1.006

Available at: https://jdc.jefferson.edu/tmf/vol4/iss1/5

This Article is brought to you for free and open access by the Jefferson Digital Commons. The Jefferson Digital Commons is a service of Thomas Jefferson University's Center for Teaching and Learning (CTL). The Commons is a showcase for Jefferson books and journals, peer-reviewed scholarly publications, unique historical collections from the University archives, and teaching tools. The Jefferson Digital Commons allows researchers and interested readers anywhere in the world to learn about and keep up to date with Jefferson scholarship. This article has been accepted for inclusion in The Medicine Forum by an authorized administrator of the Jefferson Digital Commons. For more information, please contact: JeffersonDigitalCommons@jefferson.edu. 


\section{Nonspecific Interstitial Pneumonitis in HIV-infected Patients \\ Bobbak Vahid MD, Resident, Internal Medicine 2001-2004 \\ Department of Internal Medicine, Thomas Jefferson University, Philadelphia, Pennsylvania}

A 24 year old African-American male with a history of AIDS with a recent CD4 count of $57 / \mathrm{uL}$, is admitted to the hospital with substernal chest pain and shortness of breath for the past two weeks. Dyspnea is mostly on exertion, and the patient denied productive cough or hemoptysis, fevers, chills, or night sweats. Three weeks prior to presentation, the patient underwent esophagogastroduodenoscopy, which revealed an esophageal ulcer. Biopsies did not show any specific pathology and cultures were negative. Outpatient medications include prednisone, rabeprazole, fluconazole, clarithromycin, and ethambutol, bactrim.

Vitals on admission were as follows: temperature 97.2, pulse $80 / \mathrm{min}$, and respiration rate $26 / \mathrm{min}$. On physical exam, no crackles or wheezing were found. Computerized tomography scan of the chest revealed multiple bilateral nodules, without pleural effusions or mediastinal/hilar lymphadenopathy. Bronchoscopy was performed with transbronchial biopsy; cultures obtained were negative. Transbronchial lung biopsy showed an interstitial infiltrate of mononuclear cells, predominantly lymphocytes, consistent with a diagnosis of nonspecific interstitial pneumonitis. The patient was subsequently referred to infectious disease clinic for highly active antiretroviral therapy.

\section{Nonspecific Interstitial Pneumonitis}

Interstitial pneumonitis in HIV-infected patients is most commonly caused by Pneumocystis carinii (PCP). PCP occurs in up to $50 \%$ of patients with acquired immune deficiency syndrome (AIDS) in the last 6 months of their lives $^{1}$. Sputum induction for diagnosis of PCP is associated with variable sensitivity of 50 to $95 \% .^{2-3}$. Because the test can have a negative predictive value as low as 39\%, the absence of Pneumocystis carinii in induced sputum does not reliably exclude the diagnosis of PCP. Other patients may be too ill to undergo bronchoscopy. Thus, many HIV-infected patients with pneumonitis are empirically treated without a confirmed diagnosis ${ }^{3}$. In some cases, however, pneumonitis cannot be ascribed either to known infectious agents or to malignancy. These disorders are believed to be inflammatory in origin and are grouped into two entities: lymphoid interstitial pneumonitis (LIP) and nonspecific interstitial pneumonitis (NSIP) ${ }^{4}$. In one study on 351 HIV-positive patients with pneumonitis, NSIP was the most common histologic diagnosis in patients without $\mathrm{PCP}^{3}$. Because treatment and prognosis of PCP and NSIP are different, it is important to differentiate these entities.

Nonspecific interstitial pneumonitis (NSIP) is a term applied to conditions in which there are abnormal mononuclear cell infiltrates of the lung without other explanations for the abnormality, including previous infection, malignancy, LIP or exposure to pulmonary toxic drugs ${ }^{4-7}$.

\section{Prevalence}

NSIP occurs in 5 to $11 \%$ of HIV-infected adults who present with respiratory disease $e^{3-6}$. NSIP was detected in $24 \%$ of 67 symptomatic patients without PCP, using bronchoalveolar lavage (BAL) and transbronchial biopsy (3 NSIP prevalence has been reported to be as high as $38 \%$. In this study, 41 out of 110 AIDS patients had NSIP ${ }^{3,6}$. Subclinical NSIP can also occur. Evidence of NSIP was found in 50\% asymptomatic HIV-infected patients with normal chest radiograph and CD4 count below 200 cells $/ \mathrm{mm} 3$ on transbronchial biopsies ${ }^{6}$.

\section{Clinical Manifestations}

Symptoms include dyspnea with or without cough, fever, and hypoxia $a^{4,8}$. Certain clinical descriptors are helpful in distinguishing NSIP from PCP. Patient with NSIP are more likely to have less advanced HIV infection with higher body mass, serum albumin levels, and CD 4 counts $^{3,8}$. These patients tend to have less lung inflammation, normal LDH values, and fewer involved lobes on chest radiographs (CXR) ${ }^{3}$. CXR findings may vary from normal to increased interstitial markings. Reticulonodular infiltrates have been reported in occasional cases ${ }^{5-6,9}$. Mediastinal and hilar lymphadenopathy or associated pleural effusions have not been reported in NSIP.

\section{Pathology}

NSIP is defined by the presence of chronic interalveolar septal inflammation in the absence of a specific microorganism, identified through standard histopathologic, histochemical, cytologic, and culture 
techniques (methenamine silver for P. carinii, ZielNeelsen method for mycobacteria, nuclear inclusions for CMV pneumonia) ${ }^{3}$. Pathologic findings include interstitial infiltration predominantly consisting of lymphocytes and plasma cells, fibrosis, edema, pneumocyte hyperplasia, alveolar hyaline membranes, bronchial inflammation, and thickened alveolar septae ${ }^{3-4}$. In one retrospective review of seven patient with NSIP, interstitial pneumonitis consisted of a patchy lymphocytic infiltrates composed of B cells in focal aggregates and $\mathrm{T}$ cells in a more diffuse distribution. The $\mathrm{T}$ cell population was a mixture of CD4 and CD8 lymphocytes. These findings contrast with the more extensive infiltrates of predominantly CD8 lymphocytes seen in lymphocytic interstitial pneumonitis (LIP), which occur mainly in children ${ }^{8}$.

\section{Etiology}

The etiology of NSIP is uncertain. The cytokine profile of BAL fluid samples from patients with NSIP differs from that with PCP, suggesting that NSIP is a distinct entity $^{3,10}$. In 15 NSIP patients, in-situ hybridization did not show evidence of Epstein-Barr virus (EBV) or Cytomegalovirus (CMV) infection. Whether HIV causes NSIP is uncertain. Polymerase chain reaction (PCR) testing for HIV gag and env DNA is usually positive in NISP, but also positive in HIV control patients with normal lung histology ${ }^{3}$. The role of Human herpes virus type 6 (HHV-6) is also unclear.

\section{Course and Therapy}

NSIP runs a subacute and generally benign course. Spontaneous improvement in 7-10 days has been reported $^{3}$. There is no published data available on treatment modalities, although some patients have anecdotally responded to oral steroids. Long-term survival is less than three years, prognosis primarily determined by other infective or neoplastic complications. NSIP does, however, appear to mark a clinical decline in the progression of HIV infection. The role of HAART in the treatment of this disorder is unknown ${ }^{4,8}$.

\section{References}

1. Chan, I. S. F., J. D. Neaton, L. D. Saravolatz, L. R. Crane, J. Osterberger, for Community Programs for Clinical Research for AIDS. 1995. Frequencies of opportunistic diseases prior to death among HIV-infected persons. AIDS 9:1145-1151.

2. Bigby, T. D., D. Margolskee, J. L. Urtis, P. F. Michael, D. Sheppard, W. K. Hadley, and P. C. Hopewell. 1986. The usefulness of induced sputum in the diagnosis of pneumocystis carinii pneumonia in patients with the acquired immunodeficiency syndrome. Am. Rev. Respir. Dis. 133:515-518.

3. Sattler, F., Nichols, L., Hirano, L., Hiti, A., Hofman, F., Hughlett, C., Zeng, L., Thomas Boylen, C., Koss, M. 1997, Nonspecific Pneumonitis Mimicking Pneumocystis carinii Pneumonia. Am. J. Res. Crit. Care Med. 156:912-917.

4. Dorothy A. White. 2002. Interstitial pneumonitis in HIV-infected patients. UptoDate online 10.2.

5. Stover, DE, White, DA, Romano, PA, et al. Spectrum of Pulmonary Disease Associated with the Acquired Immunodeficiency Syndrome. Am J Med 1985; 78:429.

6. Suffredini, AF, Ognibene, FP, Lack, EE, et al. Nonspecific Interstitial Pneumonitis: A Common Cause of Pulmonary Disease in the Acquired Immunodeficiency Syndrome. Ann Inter Med 1987; 107:7

7. Ognibene, FB, Masur, H, Rogers, P, et al. Nonspecific Interstitial Pneumonitis without Evidence of Pneumocystis carinii in Asymptomatic Patients Infected with Human Immunodeficiency Virus (HIV). Ann Intern Med 19888; 109:874.

8. Griffiths, MH, Miller, RF, Semple, Sj. Interstitial Pneumonitis in Patients Human Immunodeficiency Virus. Thorax 1995: 50:1141.

9. Simmons, JT, Suffredini, AF, Lack EE, et al. Nonspecific interstitial pneumonitis in patients with AIDS: Radiologic features. AJR AM J Roentgen 1987; 149:874.

10. Denis, M., and E. Ghadirian. 1994. Dysregulation of interleukin 8, interleukin 10 , and interleukin 12 release by alveolar macrophages from HIV type 1-infected subjects. AIDS Res. Hum Retrovir. 10:1619-1627. 